\title{
Research on Influence of National Folk Sports Events on Social Harmonious Development at China-Vietnam Border
}

\author{
Bikai Dong ${ }^{1}$, Yingqing $\mathrm{Hu}^{2}$ * \\ ${ }^{1}$ Guangxi Normal University for Nationalities, Chongzuo, 5322002, China \\ ${ }^{2}$ Guangxi College of Sports and Physical Education, Nanning, 520012, China \\ *Corresponding author
}

Keywords: national folk sports events; China-Vietnam border; harmonious and stable society

\begin{abstract}
This paper mainly analyzes the value of contact of Chinese-Vietnamese national folk sports events: the sports events enhance the communication between nationalities at border, ensure harmonious and stable border; promote active spiritual culture and weaken passive culture; make for trade contacts between two countries, and lay a material basis for harmony and stability; promote sports communication and cooperation between two countries; furthermore, this paper also proposes that to know the importance of national folk sports events is an important link to promote harmonious development at China-Vietnam border for readers' reference.

The sports are competitive and communicative and they greatly promote the contact between countries. As an important content of sports activity, the national folk sports events play a unique role in the contact between countries and create the value for the construction of stable and harmonious relation between countries. China and Vietnam are neighbor countries, thus both of them shall provide a stable and harmonious development environment for each other to realize national economic and social development. The national sports events have unique function in promoting the construction of friendly neighbor, thus the research on influence of national folk sports events on social harmonious development at China-Vietnam border is of great theoretical significance and practical significance. The text below will firstly discuss the importance of social harmonious development at China-Vietnam border.
\end{abstract}

\section{Importance of social harmonious development at China-Vietnam border}

To construct harmonious society is a main goal of Chinese current social development. A harmonious society can provide stable environment for national economic construction; meanwhile, the construction of harmonious society need a stable and harmonious national environment, stable and harmonious surrounding environment, and harmonious and stable relation with neighbor countries, etc.

The peace and development is the topic of the present-day world, and to construct harmonious neighbor country relation is one of important contents of this topic. The harmonious neighbor country relation can avoid outbreak of world war, and ensure that people can live and work in peace and contentment. Therefore, a harmonious neighbor country relation is the premise for construction of whole harmonious society.

Guangxi Province is located in southwest China. In terms of geographical position, Guangxi Province is connected with land in north Vietnam, and there are many similar places in history, politics, culture, and economy, etc., thus the harmonious and stable development of relation between two countries have important influence on the relation between China and whole ASEAN (Association of Southeast Asian Nations) and also have important influence on safety and stability in southwest China. In history, some misunderstanding once happened between China and Vietnam; however, after tens of years of efforts, their relation has been gradually improved and developed towards a better direction. Furthermore, the historical experience tells us that the cooperation is good for both parties while the fighting will cause a lose-lose situation. The stable and harmonious relation between China and Vietnam provides many conveniences for trade contact between two countries; when these two countries are under conflict period, many negative influences are caused 
on both parties. Therefore, we need to enhance harmonious contact between China and Vietnam so as to create a more stable environment for development of these two countries.

\section{Current situation of contact of national folk sports events between China and Vietnam}

(I) Keeping contact of folk sports events with national characteristics

In China-Vietnam border area, some national folk sports still keep their uniqueness, such as Changhawu dance in Hajie Festival of Jing Nationality, Tiaopantu in Pantu Festival of Yao Nationality, water sprinkling and Yi-nationality dance in the Torch Festival of Yi Nationality, ball throwing in the Song Festival of Zhuang Nationality, and "dance under moon” of Miao Nationality. Those sports activities happen in the place near China-Vietnam border; they have great difference with mainstream culture of respective country and obvious national character; meanwhile, they are most attractive part in the contact of national folk sports events at China-Vietnam border, and also the main part of contact of national folk sports events between China and Vietnam.

(II) Keeping contact of folk sports events with partial national characteristics

As for folk sports events with partial national characteristics, it is a kind of blending phenomenon that those sports events keep the sports feature of the nationality due to traditional influence, but have new feature due to influence by sports factors of other nationality. ${ }^{[1]}$

The national sports blending is generally mutual blending between nationalities in one country, but no communication with cross-border nationalities. The reasons which cause this phenomenon are shown as below:

Firstly, Chinese and Vietnamese people need to handle entry procedure if they want to cross border, thus the cross-border is difficult; the national concept and state concept are kept under long-term gambling state in this atmosphere;

Secondly, with gradual development of modern society, the national unique sports events become sports activity shared by multiple nationalities, such as Water-Sprinkling Festival of Dai Nationality, drum-beating dance of Yao Nationality, walking on stilts of Jing Nationality, and bull fighting of Li Nationality; the concept of ethnic group is weakened under this atmosphere.

Influenced by above reasons, most of people participate in national folk sports events due to travelling rather than promoting blending of ethnic group, which promotes the national integration in an intangible way. The sports events features are gradually weakened. ${ }^{[2]}$

(III) Realizing blending and sharing contact of folk sports events

With social development and information progress, partial Chinese and Vietnamese national folk sports activities gradually become the sports events sought by the public; the main reason is that the national sports activities have good mass base, outstanding ornamental value, participating and competitive feature, thus they conform to modern people's value pursuit for competitive sports and gradually become a kind of sports events shared by nationalities in social development. For example, the activities such as dragon boat race, lion dancing race, and martial art race are often held between China and Vietnam, which realizes blending and sharing of national sports events. ${ }^{[3]}$ With continuous social development, some national folk sports events have become the important competition content of the Asian Games, which helps national sports to step towards internationalization and makes the reputation of sports greatly improved. Furthermore, due to high entertaining and competitive features as well as conforming to the pursuit of social public for entertainment culture, the sports events only held in folk in the past are gradually developed as sports events for friendly contact between China and Vietnam, which makes national folk sports events become official and normalized and also provides great convenience for holding of national sports events in folk.

\section{Value of contact of national folk sports event between China and Vietnam}

(I) Enhancing the communication between nationalities at border, and ensuring the harmonious and stable border

The communication between nationalities at China-Vietnam border is mainly limited by border 
line of two countries, and people who want to cross the border must have the entry certificate. In historical contact, the main ways of communication between China and Vietnam include as follows:

1) Trade activities at trading ports;

2) Cross-border intermarriage, hereditary cross-border, and other activities between two countries;

3) National folk sports events held between two countries.

Therefore, through analysis, it is found that the national folk sports events are a good way of communication for nationalities at China-Vietnam border. It is able to hold various kinds of rituality activities in sports activities for the purpose of inheriting national culture; meanwhile, the nationalities of two countries also like this kind of contact, and such contact never stop in the contact history of two countries. It is recorded in relevant documents that dozens of and even hundreds of people would participate in sports activities through cross-border way while China and Vietnam held sports events respectively; in this kind of folk sports events, a kind of mutually friendly relation will be established to enhance communication between nationalities. ${ }^{[4]}$

(II) Promoting active spiritual culture and weakening passive culture

The sports are positive, thus the holding of folk sports events between China and Vietnam must spread positive sports culture and resist backward ignorance culture, which will be good for cultural construction at border. In history, Chinese southwest border area belongs to high-occurrence area with eroticism, gambling, and drug, and the "Golden Triangle" area is the most serious area; this positive and backward cultural atmosphere seriously influences local economic development and public security, and causes great harm on villages and communities at border. However, through developing national folk sports events, it is able to promote positive culture and restrain the spreading of bad culture at border area so as to provide a stable security environment for people at border area. ${ }^{[5]}$ Compared to other projects, the charm of national sports events lies at communication; through participating in events, people living at border can change the backward culture existing in their nationality.

(III) Making for trade contacts between two countries, and laying a material basis for harmony and stability

The historical experience tells us that the economic development at China-Vietnam border would be seriously influenced while there existed temporary national conflict between China and Vietnam; however, the economic and cultural construction would be continued while two countries kept friendly relation. Therefore, the relation between two countries has great influence on economic development at border.

Through contact of national folk events, people of two countries participate in events through cross-border way, which will drive people of two countries to establish a friendly neighbor relation and lay a good foundation for future trade contacts between two countries. Besides, the trade contacts between nationalities of China and Vietnam are generally the main economic income of people at border, and also important support for local finance. The two ports Dongxing and Pingxiang established by China by virtue of contact advantage at China-Vietnam border have obtained quick development under this stable and harmonious atmosphere. ${ }^{[6]}$

Due to unique competition and communication, the national folk events enhance both parties' friendship and mutual trust relation, and improve the success rate for both parties' trade negotiation; meanwhile, large quantity of trade contacts are contained in the contact of sports events, which provides convenience for people who making trade at border. The contact of national folk sports events can also help to cultivate common ethnic belief; in cultivating process, the state concept will be greatly weakened and living in harmony between nationalities can always become mainstream view of value; under this atmosphere, the friendship between people at China-Vietnam border will be deepened, which will provide convenience for trade contacts.

Through border trade, people living at China-Vietnam border will benefit, and people's living level will be improved in trade contacts, which will lay a material basis for harmony and stability at China-Vietnam border.

(IV) Promoting sports communication and cooperation between two countries 
1. Becoming important content of sports communication between two countries

The sports communication between two countries not only includes large-scale sports events organized by government, but also includes the national folk sports events organized by people at border; the folk sports events can help to realize establishment of China-Vietnam free trade area, enhance sports communication between two countries, and enhance people's friendship at border. Compared with sports events held by government, the national folk sports events are convenient and quick, and widely participated by people at border. In the process of participating in sports, people can also have suitable trade behaviors, which is very good for economic development at China-Vietnam border.

Take dragon boat race held in Nanning City and Fangchenggang City, Guangxi Province as an example: with social development, it has broken through bottleneck of national sports and gradually becomes popular sports competition event. Although the dragon boat race is not official event of the Asian Games at present, it is easier to attract border people's attention through holding this kind of dragon boat race, and the border people will have higher enthusiasm and more convenient way to participate.

2. Becoming the basis of cooperation with other sports

The communication of national folk sports events between China and Vietnam has begun at an early time. In Tang dynasty, China held many national folk sports events such as dance accompanied by music, Cuju (ancient football), archery, and pitch-pot with Vietnam; through communication, various kinds of sports events were spread to Vietnam and Southeast Asia region, which promoted development of sports events. Furthermore, through holding those sports events, other kinds of sports events will increase in contacts. For example, at the very beginning, China and Vietnam mainly held dragon boat race; with social development, the sports events were gradually developed archery competition, national events in Lantern Festival, and cock fighting. In this way, the national folk sports events between two countries are developed towards diversified direction.

As these two countries hold more and more national folk sports events, some sports events with high international attention also join; for example, China and Vietnam have held football game for many years, and those events are all held on the basis of developing national sports events. Through holding more and more sports events, various kinds of contact at China-Vietnam border will increase, and the trade contacts between two countries will increase accordingly. ${ }^{[7]}$

3. Promoting the construction of sports facility condition at border

Now that national folk sports events are held, certain sports facilities must be constructed, thus the government is required to enhance improvement on sports facility condition; meanwhile, those sports facilities can provide convenient chance for border people's daily physical exercise. For example, in 2008, China invested RMB 797 million yuan for national sports project in Hongshui River Basin; this project could be built as sports corridor at China-Vietnam border to provide more convenience for people at border to engage in physical exercise. Furthermore, the construction of sports facilities can bring more employment positions; therefore, through construction of sports facilities, it is able to provide large quantity of employment positions for people living at China-Vietnam border, solve the problem of employment difficulty, and improve their annual income, economic and living level.

\section{Conclusion}

It can be seen through above analysis that the functions of national folk sports events on harmonious and stable development at China-Vietnam border mainly include: enhancing the communication between nationalities at border, ensuring harmonious and stable border; promoting active spiritual culture and weakening passive culture; making for trade contacts between two countries, and laying a material basis for harmony and stability; promoting sports communication and cooperation between two countries. Only after we practically know the importance, we can pay attention to national folk sports events in actual life, truly realize harmonious and stable development at China-Vietnam border, and create a stable and harmonious border environment for economic and social development of two countries. 


\section{References:}

[1] Wang Daili: Analysis on Globalization and National Cultural Identification [J], Journal of Guizhou Provincial Committee Party's School of C.P.C, 2007, 12(06): 33-36.

[2] Liao Guo: Discussion on Construction of Two Corridors and One Economic Belt and Tourism Cooperation Between China and Vietnam [J], Journal of Guangxi Normal University, 2006, 09(11):42-46.

[3] Li Defang: Discussion on Action and Application of Sports Diplomacy - take Beijing Olympic Games as an example [J], Contemporary International Relations, 2008, 12(10):55-60.

[4] Gu Xiaosong: Normalization after Resentment - Review and Prospect to China-Vietnam Relationship over 60 Years [J], Around Southeast Asia, 2010, 12(11): 25-33.

[5] Liu Guangtao: Discussion on Globalization and Change of Cultural Function of Sports [J], Sports Culture Guide, 2013,09(12):10-11.

[6] Huang Jialian: Research on Cooperative Development Between National Sports Corridor in South China and Neighboring Countries in ASEAN under New Trend [J], Journal of Shandong Institute of Physical Education and Sports, 2009, 10(17):33-34.

[7] Xie Xiongjian, Liu Chuang, Zhao Fang: Research on Construction of Nationwide Fitness Project at China-Vietnam Border (Guangxi) and Construction of Harmonious Neighbor Country Relation [J], Sports Science \& Technology, 2010, 09 (19): 79-80. 